\section{Em defesa da reforma psiquiátrica: por um amanhã que há de nascer sem pedir licença}

\section{In defense of psychiatric reform: for the dawn of a new unavoidable} future

Ilana Lemos de Paiva

Doutoranda do Programa Integrado em Psicologia Social da UFRN/UFPB, Bolsista Capes Caixa Postal 1524 - Campus Universitário Lagoa Nova, 59072-970 Natal - RN - Brasil ilanalp@bol.com.br

Oswaldo H. Yamamoto

Professor titular do Departamento de Psicologia da Universidade Federal do Rio Grande do Norte

Caixa Postal 1524 - Campus Universitário Lagoa Nova, 59072-970 Natal - RN - Brasil ohy@uol.com.br
PAIVA, Ilana Lemos de; YAMAMOTO,

Oswaldo H. Em defesa da reforma psiquiátrica: por um amanhã que há de nascer sem pedir licença.

História, Ciências, Saúde - Manguinhos, Rio de Janeiro, v.14, n.2, p.549-569, abr.-jun. 2007.

Este trabalho constitui um estudo acerca do processo histórico de implantação da reforma psiquiátrica no estado do Rio Grande do Norte, destacando-se os atores envolvidos, sua trajetória, conquistas e avanços, e as perspectivas atuais desse movimento em concretizar os ideais de ressocialização do portador de doença mental. Foi necessário compreender $\mathrm{o}$ processo ocorrido na Secretaria Municipal de Saúde, a partir de 1992, por essa experiência ter impulsionado as reflexões sobre a reforma psiquiátrica em todo o estado. Seguiu-se a análise documental de relatórios, legislações e prontuários, bem como a coleta de depoimentos dos envolvidos no processo, buscando construir a identidade dos atores sociais e analisar sua percepção dos fatos, ressaltando congruências e incongruências a respeito da história da reforma psiquiátrica local.

PALAVRAS-CHAVE: reforma psiquiátrica; saúde mental; reabilitação psicossocial.

PAIVA, Ilana Lemos de; YAMAMOTO, Oswaldo H. In defense of psychiatric reform: for the dawn of a new unavoidable future. História, Ciências, Saúde - Manquinhos, Rio de Janeiro, v.14, n.2, p.549-569, Apr.-Jun. 2007.

This work comprises a study into the historic process of implementation of psychiatric reforms in Rio Grande do Norte state, highlighting the agents involved, their careers, achievements and progress and this movement's current prospects for realizing the ideal of reintegrating mental health patients in society. It is necessary to comprehend the process that took place within the Municipal Health Department starting in 1992, since this experience was the driving force for reflections upon psychiatric reform across the state. This is followed by a documental analysis of reports, legislation and dossiers, as well as the collection of depositions by people involved in the process with a view to building up the identity of the social agents and analyzing their perceptions of the facts, highlighting congruencies and incongruencies concerning the history of the local psychiatric reform.

KEYWORDS: psychiatric reform; mental health; psychosocial rehabilitation Juliano Moreira and Gazeta Médica da Bahia 
A partir da década de 1990, o processo de reestruturação da as sistência psiquiátrica no Brasil teve grande desenvolvimento, respaldado pelas portarias ministeriais que apontavam para a criação de uma rede de cuidados em saúde mental, incluindo Núcleos e Centros de Atenção Psicossocial - NAPS e CAPS -, ambulatórios em saúde mental, centros de convivência, leitos de curta permanência em hospitais gerais, emergências em pronto-socorro geral, residências terapêuticas etc.

Vários municípios e estados de todo o país se adequaram às novas normatizações na área de saúde mental, o que fez com que os serviços de atenção diária aos portadores de sofrimento psíquico passassem de três para 295, no período compreendido entre 1990 e 2001. Nesse contexto foram criados, em Natal, no Rio Grande do Norte, os NAPS e CAPS, estratégias municipais para efetivação da Lei Paulo Delgado.

No entanto, ao propor-se uma reformulação no campo da assistência à saúde mental, logo renasceram os medos da sociedade que pareciam controlados pelo manicômio. Os mitos de periculosidade e invalidação social relacionados ao 'louco' compõem grandes obstáculos aos avanços. Além disso, existe a resistência dos próprios profissionais, que se agarram a suas 'verdades científicas' e temem perdê-las. No Brasil, ainda encontramos um terceiro 'inimigo', a chamada 'indústria da loucura' (Lobosque, 2001).

Apesar desses 'inimigos', os portadores de doença mental tiveram seus gritos - antes contidos - escutados por muitos e começaram a assistir a 'novas manhãs renascendo', longe dos espaços claustrofóbicos dos hospitais psiquiátricos. Foi uma longa trajetória que envolveu, por um lado, derrotas e retrocessos, e por outro importantes conquistas e avanços. Resta-nos saber se a lei da reforma psiquiátrica está sendo aplicada nos municípios e como seus pontos essenciais estão sendo efetivados. Importa observar, também, como se deu a passagem das leis para seu planejamento e sua execução.

Eventos recentes no campo da saúde mental mostram que, após períodos de avanços significativos, talvez o processo de reforma psiquiátrica tenha ficado mais lento diante de dificuldades que outrora não existiam. O que se espera de uma reforma efetiva é que ela abandone em definitivo o modelo anterior, de modo a banir do ambiente psquiátrico situações em que tendências contraditórias duelam pela 'razão' no universo da loucura. É chegado o momento de questionar, afinal, sobre os (novos ou antigos) 'inimigos ocultos' da reforma psiquiátrica no nosso país, responsáveis por sua estagnação. Faz-se mister repensar as práticas implantadas, avaliar os novos serviços, analisar o poder de articulação do movimento com setores políticos e sociais, identificar as barreiras e tentar avançar nas propostas. 
Este estudo objetiva contribuir para essa avaliação mediante uma análise sobre o processo da reforma psiquiátrica no Rio Grande do Norte, com foco nos atores envolvidos, sua trajetória, conquistas e avanços, bem como as perspectivas do movimento no sentido de concretizar o ideal de ressocialização do portador de doença mental. Acreditamos que, ao enfocar a implantação da reforma no âmbito estadual, este estudo pode evocar algumas reflexões sobre a reforma psiquiátrica brasileira. Afinal, a reforma psiquiátrica no Rio Grande do Norte é um exemplo do que vem se configurando no país, ou seja, apesar de suas especificidades, ela integra um processo histórico de nível nacional, no campo da saúde mental.

A estratégia desta pesquisa consistiu na análise de relatórios, legislações e prontuários e na coleta e análise de depoimentos de pessoas envolvidas. A perspectiva adotada foi a de que os depoimentos orais, além de complementar as lacunas das fontes escritas, possuem valor próprio na tentativa de reconstrução de um processo vivido historicamente. Assim, por meio da história oral buscouse construir a identidade dos atores sociais e sua percepção dos fatos, ressaltando-se congruências e incongruências nos depoimentos a respeito do percurso da reforma psiquiátrica.

Trabalhamos em defesa da reforma psiquiátrica por estar ela imbuída dos ideais de uma sociedade realmente igualitária e humanizada, que prima pela reinserção social de excluídos como os portadores de doença mental, conforme os princípios democráticos. Enfim, por uma sociedade livre de opressão, preconceito e ignorância. Que rumos terão tomado os ventos favoráveis que anunciavam o início de uma revolução conceitual na área de saúde mental? O que aconteceu com um projeto que se tornava referência nacional e, alguns anos depois, parece ter se imobilizado no tempo?

\section{A assistência à saúde mental no município de Natal}

A Secretaria Municipal de Saúde (SMS) de Natal foi criada em 1986, sob a influência da nova política de saúde que estava sendo gestada no país. Como reflexo das resoluções da $2^{\text {a }}$ Conferência Nacional de Saúde Mental, que preconizou a criação de uma rede de atenção integral de saúde mental em substituição aos hospitais psiquiátricos, organizou-se formalmente, no ano de 1992, a assistência à saúde mental na rede pública do município. Até então os serviços de saúde mental de Natal restringiam-se à oferta de leitos de hospitais psiquiátricos. A SMS buscou estabelecer um modelo de atenção que tivesse como referência os princípios decorrentes do projeto de reforma sanitária brasileira: universalização, democratização, hierarquização, regionalização e integralidade das ações. A proposta visava estruturar os serviços de atenção em saúde mental em seus diversos níveis de assistência, focalizando prevenção, pro- 
moção, tratamento e reabilitação. Assim, em um sistema integrado de atendimento, a saúde passaria a ser assistida em três níveis de atenção.

Para o propósito de observar a evolução dos conceitos de assistência à saúde mental e as conseqüentes transformações ocorridas em Natal, é importante resgatar a história da estruturação desses serviços. A implantação da reforma psiquiátrica no município foi dividida, neste estudo, em quatro momentos distintos. O primeiro corresponde aos anos de 1986 a 1992, e caracteriza-se como a etapa de planejamento e organização de uma nova rede de assistência em saúde mental.

\section{Planejamento e organização da rede de assistência em saúde mental}

Em 1986, a partir da $8^{a}$ Conferência Nacional de Saúde, as discussões ampliadas em torno do conceito de saúde passaram a envolver também categorias profissionais como psicólogos, assistentes sociais e enfermeiros. Como resultado dessas discussões, propôs-se uma reorganização dos serviços que anunciava a importância da ação interdisciplinar no âmbito da saúde e reconhecia a imprescindibilidade das ações realizadas por diferentes profissionais - conforme justifica a resolução 218, de 6 de março de 1997, do Conselho Nacional de Saúde.

Em Natal, o profissional de psicologia foi um dos primeiros a ingressar na SMS com o intuito de realizar ações voltadas para a saúde mental, tornando-se um importante ator político no processo de reforma psiquiátrica. Realizava-se, nesse período, um diagnóstico sanitário para a implantação de unidades de saúde no município, no qual avaliavam-se as condições sanitárias e a qualidade de vida da população, incluindo questões relacionadas a problemas emocionais, conflitos familiares, violência contra a mulher, dificuldades de aprendizagem de alunos da rede pública, alcoolismo e outras dependências - enfim, os diversos agravos relacionados à saúde mental da população.

Não obstante já tivesse a psicologia ocupado seu espaço na rede de saúde pública e assistência de saúde mental de várias localidades, em Natal ela desempenhou papel protagonista, principalmente devido à falta de psiquiatras afinados com as idéias inovadoras, conforme atesta este depoimento:

Houve pouquíssima renovação no quadro da psiquiatria em Natal. Não foi por acaso que durante muito tempo não houve concursos na universidade para a área de psiquiatria. Não tinha residentes... Não tivemos novos quadros de profissionais com idéias novas para atuar no campo. Isso reforçou muito a visão mais 
tradicional da psiquiatria, que defendia o asilo, o espaço do hospital psiquiátrico. (Paulo Rocha, ex-secretário de Saúde de Natal)

Nesse contexto chegaram os primeiros psicólogos à SMS, em 1987. No ano seguinte, já com um grupo desses profissionais nas unidades, realizou-se o $1^{\text {o }}$ Seminário de Saúde Mental, que teve como um dos objetivos reforçar a discussão do papel do psicólogo na assistência à saúde mental. $\mathrm{O}$ depoimento a seguir deixa claro que a psicologia e a atenção à saúde mental ainda eram, à época, questões embrionárias na rede de saúde pública.

Tínhamos uma certeza naquele momento: precisávamos nos instrumentalizar com recursos e informações, acolher bem, atender bem do ponto vista clínico, mas sem perder de vista a contextualidade do paciente. E que o usuário... é o indivíduo, como é também um grupo coletivo de uma escola, um grupo de mães, um grupo de jovens... Todas as questões seriam em parte relevantes para a formulação de necessidades, de problemas determinantes para o usuário, para que ele pudesse levar até uma unidade. (Elisabete Freitas, ex-coordenadora de Saúde Mental)

Naquele momento discutia-se o planejamento das ações desses profissionais, pautado na prevenção e na educação em saúde. Além disso, as psicoterapias eram também instrumentos presentes nas unidades de saúde de Natal. O psicólogo era "uma espécie de clínico geral" da unidade e devia estar disponível para atender qualquer tipo de demanda em saúde mental, fosse ela da criança, do adolescente ou do adulto envolvendo neuroses, psicoses ou problemas ligados à depressão e alcoolismo.

Eu trabalhava com psicanálise na unidade de saúde de Pajuçara atendendo criança, adolescente e adulto. Depois passei a atender só adolescente e adulto, por não me identificar com o trabalho com crianças. Inicialmente eu atendia crianças por exigência da Secretaria, pois éramos uma espécie de clínicos gerais dentro da unidade. (Wagner Lima, ex-psicólogo do NAPS)

Uma das questões mais relevantes para a definição do papel do psicólogo em uma unidade básica de saúde refere-se a possibilidade de integração de suas atividades ao conjunto de ações ali desenvolvidas. Para Silva (1998), o modelo tradicional de psicoterapia tem impedido o psicólogo de desenvolver ações de atenção primária à saúde. O que se observa na prática desses profissionais, desde a sua entrada na rede de saúde pública até os dias atuais, é um conceito de saúde 'psicologizante', que exclui a esperada ação integrada.

A partir de 1988, os psicólogos começaram a se tornar referência na rede de saúde pública de Natal, ao se responsabilizarem pelas chamadas atividades de saúde mental. Esse grupo viria a consti- 
tuir, posteriormente, a atual Coordenação de Saúde Mental do município. Entre 1989 e 1990 ocorreu a primeira etapa de municipalização, processo de organização política, social, geográfica e econômica no qual o poder e o planejamento em saúde foram descentralizados. Esperava-se que, à medida que avançasse a municipalização dos serviços e aumentasse o número de trabalhos realizados por áreas distritais, mais seriam conhecidos os problemas da população e, por conseqüência, mais questões relacionadas ao campo social e à saúde mental emergiriam.

Foi a partir do trabalho de prevenção e tratamento, bem como das intervenções terapêuticas nas Unidades Básicas de Saúde (UBS), que se abriram novos horizontes na assistência à saúde mental, porém sem se saber ao certo onde se queria chegar.

Então, gradativamente, de acordo com o perfil epidemiológico de cada unidade, foram sendo desenvolvidos trabalhos excelentes, seja com adolescentes, seja com gestantes, seja com um grupo de pessoas que estava com um quadro mais depressivo. E aí começaram a surgir, na unidade, questionamentos, confusões - eu diria até convulsões - sobre o papel do psicólogo. (Elisabete Freitas, ex-coordenadora de Saúde Mental; grifos nossos)

Como era esperado, a equipe se via na tarefa de atender a uma população que trazia cada vez mais demandas para a área de saúde mental das UBS. Estas, entretanto, não estavam suficientemente instrumentalizadas para as novas solicitações que batiam à sua porta. Egressos de hospitais psiquiátricos, psicóticos e neuróticos graves chegavam às UBS, cujas equipes não se consideravam preparadas para atender, por questões de estrutura física da unidade ou por características da formação dos profissionais. O depoimento anterior expressa uma certa confusão a respeito do papel do psicólogo nesse serviço, não só por parte dos psicólogos, que se ressentiam de uma formação melhor, como também por parte de outros profissionais da unidade, que viam os psicólogos como 'extintores de incêndios' ou 'milagrosos', capazes de darem conta de problemas que, na unidade, ninguém mais conseguiria resolver.

Na realidade, o papel do psicólogo nas unidades de atenção primária não parece ter sido ainda de todo definido:

Acho que a prática profissional terminou reproduzindo, nas unidades, muito dos consultórios... E é a reprodução de um comportamento clássico: "Eu fico no meu consultório, atendo cinco ou seis pessoas e vou embora; minha responsabilidade é restrita àquelas seis pessoas que entraram ali." (Maristela Pinheiro, coordenadora de Saúde Mental de Natal)

Mais uma vez deparamos, no depoimento, com dificuldades relacionadas à prática da psicologia. De fato, a literatura aponta que 
parece haver uma mera transposição, para a saúde pública, do modelo hegemônico de atuação clínica, desconsiderando-se as inúmeras implicações disso decorrentes. Segundo Silva (1998), tal modelo de atuação torna-se descontextualizado na rede integrada de atenção à saúde, e priorizam-se atividades individuais, de consultas, em detrimento de ações em equipe. Em outras palavras, as ações derivadas da clínica têm tomado o lugar de atividades dirigidas ao nível de atenção esperado. A autora ainda atribui essa tendência à formação profissional dos psicólogos, pois ela "tem levado à manutenção de um modelo único de atuação" (p. 35). Não se incluem, no currículo de formação do psicólogo, discussões acerca do contexto social, das características 'reais' da população, ou temas sobre saúde pública e instituições públicas. Se fossem abordadas, tais questões evitariam a concepção do indivíduo como sujeito a-histórico e associal, a ser submetido às técnicas psicoterápicas.

Não se poderia, porém, atribuir apenas ao profissional de psicologia as dificuldades, em Natal, de assistência ao portador de doença mental. Durante a capacitação desses profissionais para os serviços, e diante da precariedade das condições de atendimento, surgiram propostas para melhor estruturar o setor de saúde mental. Entre elas constava a implantação de um centro que funcionasse 24 horas para atender às urgências, um grande problema para os profissionais que lutavam contra a internação psiquiátrica compulsória. A idéia, baseada em outras experiências, era criar um Centro 24 Horas em cada distrito sanitário de Natal, com atendimento em tempo integral, plantonistas à noite e leitos de curta permanência para acolher doentes em crise. Nesses centros, em outros horários, o usuário também teria atendimento individual ou em grupo.

Em 1992 a SMS promoveu um segundo concurso, permitindo que novos profissionais se integrassem à rede básica. Contemplava equipes mínimas de saúde mental, conforme preconizado pela Organização Mundial de Saúde. A partir de então, enfermeiros, assistentes sociais e outros profissionais médicos juntaram-se aos psicólogos nesse processo de transformação.

Aí percebemos que outros profissionais estavam preocupados com a saúde mental, não só os psicólogos. O psicólogo perdeu a sua onipotência, porque não era mais apenas ele a dar conta do problema. As portas se abriram para outras categorias, e começamos a perceber que tínhamos, no país, um problema sério de saúde pública, de saúde mental: a segregação social do doente mental, um modelo de atenção voltado para a doença, excessivamente medicamentoso e isolador. (Elisabete Freitas, ex-coordenadora de Saúde Mental)

Com o fortalecimento dessas equipes - graças, segundo depoimentos de seus componentes, à credibilidade que ganharam com 
suas propostas e ações -, tomou corpo a idéia de uma rede de serviços de atenção integral em saúde mental. Diversas outras oficinas foram realizadas, o que culminou na $1^{\underline{a}}$ Conferência Municipal de Saúde Mental, em outubro de 1992, com a participação de quinhentos profissionais da área e o apoio do Ministério da Saúde, em parceria com a Universidade Federal do Rio Grande do Norte.

No mesmo ano de 1992 as discussões em torno da criação de novos dispositivos de atenção em saúde mental já se estendiam por todo o país, principalmente em decorrência de experiências exitosas em vários municípios. Também na mesma época o Ministério da Saúde lançou portarias normativas que subsidiaram as secretarias estaduais e municipais na implantação desses dispositivos, em especial a portaria 224, de 29 de janeiro de 1992, publicada no Diário Oficial da União em 30 de janeiro de 1992, que criou os serviços de saúde mental NAPS/CAPS. Tendo por diretrizes os princípios da reforma sanitária e preconizando métodos e técnicas terapêuticas nos vários níveis de complexidade assistencial, a portaria estabelece que essas unidades de saúde mental devem oferecer cuidados intermediários entre o regime ambulatorial e a internação hospitalar, realizados por uma equipe multiprofissional, e seu funcionamento deve ser ininterrupto durante os sete dias da semana, podendo também contar com leitos de repouso eventual.

Mediante tais portarias - e sobretudo após a Conferência Municipal de Saúde Mental - deliberou-se uma reestruturação da assistência na área, com a idealização de uma rede hierarquizada e descentralizada de serviços, sendo contemplados os princípios da reforma psiquiátrica de uma forma mais efetiva. Em novembro de 1992 foi lançada a Proposta de Reorganização da Atenção em Saúde Mental no Município de Natal, documento que propunha um sistema integrado de atendimento, por meio do qual a saúde mental passava a ser assistida em três níveis de atenção, conforme mencionado anteriormente. Por uma rede articulada de serviços, o projeto da SMS contemplava policlínicas especializadas, os mencionados Centros de Atendimento 24 horas, leitos psiquiátricos em hospital geral, Centros de Atenção Psicossocial e abrigos protegidos, entre outros. O trabalho seria multidisciplinar, com os psicólogos à frente desse planejamento. Iniciava-se o segundo momento da reforma psiquiátrica no Rio Grande do Norte, o período de implantação das propostas, que corresponde aos anos de 1993 a 1995.

\section{Implantação das propostas reformistas}

Nas unidades básicas foram criados setores de referência em saúde mental e em dependência química. No mesmo contexto iniciouse a implantação do NAPS, que seria um dispositivo intermediário entre a UBS e o hospital. A princípio, o objetivo era tornar o NAPS 
um núcleo de atendimento integral a funcionar ininterruptamente. Suas principais atividades seriam o atendimento a pacientes com distúrbios psiquiátricos graves, na faixa etária de 15 e 60 anos, alcoolistas e drogaditos em surto psicótico, além de investigações clínico-epidemiológicas e organizacionais voltadas para uma clientela com maiores comprometimentos psíquicos. Pretendia-se também tornar o NAPS uma referência para os ambulatórios de saúde mental do Sistema Único de Saúde (SUS). A equipe deveria ser composta por assistente social, arte-educador, clínico-geral, enfermeiro, farmacêutico, educador físico, nutricionista, psicólogo, psiquiatra, auxiliar de enfermagem, agente administrativo, cozinheiro, auxiliar de cozinha, auxiliar de serviços gerais e vigia.

Os critérios de funcionamento do NAPS foram exaustivamente discutidos, mas o projeto demorou um pouco para sair do papel, em parte devido à polêmica promovida pelos psiquiatras locais em torno dele:

Isso gerou problemas polêmicos no campo da psiquiatria em Natal... De certa forma houve muita pressão e ameaças. Por exemplo, se o médico dava um depoimento no jornal, os psiquiatras queriam que o Conselho de Medicina atuasse contra ele, por ser favorável à reforma psiquiátrica. (Elisabete Freitas, ex-coordenadora de Saúde Mental)

Havia muita resistência por parte dos diretores de hospitais psiquiátricos, públicos e privados, e eles faziam pressão para inviabilizar o projeto. Quando começamos a trabalhar no NAPS, teve um período em que havia um policial na porta, porque o diretor na época, o psiquiatra Hilton Vilas Boas, estava sendo ameaçado e precisava andar com segurança. (Wagner Lima, expsicólogo do NAPS)

O problema é que já houve abaixo-assinado aqui, de donos de hospitais, duas ou três vezes, exigindo a substituição dessa equipe por psiquiatras. Pediam que retirassem os que faziam a 'política' dos chamados NAPS e os substituíssem por psiquiatras representantes da rede hospitalar... (Maristela Pinheiro, coordenadora de Saúde Mental)

$\mathrm{Na}$ realidade, a polêmica ultrapassava a questão da concordância ou não com os princípios da reforma psiquiátrica. O que estava em jogo era a necessária 'retirada' de leitos da rede privada conveniada com o SUS, em número equivalente àqueles a serem criados nos serviços 24 horas.

Quando nós fizemos esses serviços, eles podiam ser credenciados como serviços 24 horas. Para implantar esses serviços, seria preciso credenciar leitos. Nós temos um quantitativo de leitos definido pelo número da população... A retirada deles deveria ser 
dos hospitais privados. Porque é assim: o SUS tem uma cota de leitos; quando ele não atinge essa cota na sua rede, contrata leitos privados. Se estou criando novos serviços, tenho que retirar leitos do setor privado para colocar neles... Nós queríamos trabalhar com essa perspectiva, de já implantar um serviço com uma retaguarda de leitos 24 horas. Porque num momento de crise, sem leitos de emergência em hospitais gerais, seria uma tentativa de dar um passo até maior do que o que foi o primeiro serviço... Mas nós não tivemos, naquele momento, força política para retirar esses leitos do hospital privado para os serviços. (Maristela Pinheiro, coordenadora de Saúde Mental; grifos nossos)

Portanto não se conseguiu implantar, em Natal, os Centros 24 horas, e modificou-se o projeto inicial para o que configura hoje o NAPS. A Coordenação de Saúde Mental chegou a alugar uma casa durante um ano, aguardando condições financeiras e administrativas para implantar o projeto, mas apesar do apoio do novo prefeito, Aldo Tinoco, à proposta da Secretaria, os interesses dos donos de hospitais falaram mais alto naquele momento. $\mathrm{O}$ depoimento de Paulo Rocha, ex-secretário de Saúde de Natal, explicita muito bem as dificuldades e as contradições enfrentadas na época:

É importante lembrar que esse movimento não foi linear. Esses movimentos históricos de reforma social têm avanços e dificuldades. Por um lado, tínhamos as leis favoráveis, essa grande mobilização popular, a Constituição. Mas havia resistências ao processo, por parte de setores ligados à área hospitalar. E isso se agravou no governo Collor, no início dos anos 90. Houve uma grande dificuldade de avançar naquele momento. Dois anos se passaram até que fossem promulgadas as leis orgânicas de saúde. Ele vetou partes delas, principalmente no que dizia respeito à participação social e à transferência de recursos. Isso favorecia também esses setores que obstaculizavam a idéia da reforma psiquiátrica.

Em 1994 foi implantado o primeiro NAPS, na zona leste de Natal, com capacidade para atender 60 usuários. Em seu primeiro ano de funcionamento ele foi procurado por 147 pessoas, provenientes de todos os distritos sanitários da cidade, e criaram-se listas de es-

${ }^{1}$ Dados colhidos dos prontuários e do livro de triagem do ano de 1994, do NAPS-Leste. pera para ingressar no serviço. ${ }^{1}$ As dificuldades eram superadas pelo otimismo da equipe:

Depois de muito tempo... passamos um ano com a casa alugada, depois mais seis meses para virem os móveis e a casa funcionar. Apesar do apoio do prefeito Aldo Tinoco, esse processo foi um parto a fórceps, muito demorado... (Wagner Lima, ex-psicólogo do NAPS)

Em Natal, a reforma psiquiátrica representou inicialmente um avanço. Em 1992 começamos a fazer um plano de reestruturação 
2 A portaria 336 do Ministério da Saúde normatizou a implantação desses novos serviços, até mesmo organizando as nomenclaturas de acordo com as características de cada serviço (CAPS 1, CAPS 2 etc.), mas a mudança ainda não havia sido efetivada em Natal. em saúde mental e fizemos o projeto do NAPS, com muitas dificuldades, porque a saúde pública como um todo tem muitas dificuldades. Mas tinha uma equipe batalhando por isso, com a Betinha [Elisabete Freitas] à frente. Então, nós começamos com uma estrutura superprecária; tínhamos a casa mas não tínhamos os móveis. Eram muitas dificuldades mesmo, mas estávamos tentando e a equipe era muito boa. (Aparecida França, ex-diretora do NAPS-Leste e secretária de Saúde de Natal)

Como a demanda ao serviço era muito grande, foi implantado, em 1995, mais um núcleo em Natal, o NAPS-Oeste, e um Centro de Atenção Psicossocial, criado para atender exclusivamente a dependentes químicos e alcoolistas. Sobre a implantação do NAPSOeste, o depoimento a seguir revela as dificuldades na implantação de um serviço que não teve tanto tempo para preparar seus profissionais - ao contrário de sua proposta original -, o que acabou causando algumas confusões de papéis, como veremos adiante:

Quando cheguei no NAPS-Oeste, em 1995, ele funcionava dentro da unidade de saúde da Cidade da Esperança. Quando foi inaugurado, tinha um salão com algumas cadeiras e um som e tudo se passava naquele espaço: reuniões administrativas, oficinas... Depois foi alugada uma casa e começou a funcionar assim: os usuários e a boa vontade dos técnicos, que nem sabiam direito o que era o NAPS. (Eline Montenegro, ex-psicóloga do NAPS)

A essa altura convém um esclarecimento, já que as terminologias utilizadas para designar esses serviços variaram no país. ${ }^{2} \mathrm{O}$ NAPS em Natal seguiu os mesmos princípios básicos que orientaram a constituição do CAPS na cidade de São Paulo, isto é, seria apenas um plano inicial, uma vez que ainda aceitava co-existir com o hospital psiquiátrico. Configurava-se como uma alternativa à não-internação, entretanto sem substituí-la por completo. (Amarante, 1997; Amarante et al., 2001).

Os NAPS/CAPS passaram a funcionar em horário integral, das sete às 18 horas, acolhendo os usuários nas diversas atividades e oferecendo três refeições diárias. Inicialmente, as pessoas que procuram os serviços passam por uma triagem para acolhimento e, à medida que freqüentam a casa, integram-se às atividades. Caso a demanda não seja para os serviços, o usuário é encaminhado a uma instituição para tratamento adequado. Somente indivíduos maiores de 14 anos são assistidos nesses serviços, e eles chegam espontaneamente ou por demanda referenciada. A assistência é definida como psicossocial e multidisciplinar, exercida através de intervenções terapêuticas individuais (atendimento clínico, psiquiátrico, psicológico, nutricional etc.) e grupais, através de oficinas (artes plásticas, música, argila, beleza, esporte, poesia, psicodrama, coral, jardinagem e horta, escrita, origami, dança, teatro, trabalhos 
manuais, rádio, jornal), espaços coletivos (debates sobre saúde e sociedade, Espaço Aberto, Bom Dia/Boa Tarde NAPS, assembléia com técnicos, usuários e familiares) e espaços socioculturais (apresentações dos corais em eventos públicos, realização de festas comemorativas, passeios culturais, visitas a museus, pontos turísticos e históricos da cidade, entre outros). O projeto prevê, ainda, ações interinstitucionais, por meio das quais seria promovida a interação dos usuários dos NAPS/CAPS com diversos setores da sociedade, como instituições públicas e privadas, e ações de inclusão/reinserção social, que possibilitariam o retorno à escola, ao trabalho e ao convívio familiar e o resgate da cidadania.

Os anos de 1996 e 1997 configuraram o terceiro momento da reforma psiquiátrica em Natal, um período da afirmação dessa nova proposta de atenção em saúde mental.

\section{Consolidação e afirmação do projeto de reforma psiquiátrica}

Após a criação desses serviços, surgiram dados bastante positivos a respeito da redução das internações psiquiátricas, o que aumentou a credibilidade dos NAPS perante a sociedade e os órgãos públicos. É importante ressaltar que esses núcleos tornaram-se as principais referências da proposta de reforma psiquiátrica no estado.

Os Gráficos 1 e 2 mostram dados obtidos no NAPS-Leste e no NAPS-Oeste, entre os anos de 1994 e 2001, sobre o número de internações de usuários antes e depois do início do tratamento nos NAPS.

Gráfico I: Histórico de internação psiquiátrica dos usuários antes do tratamento nos NAPS

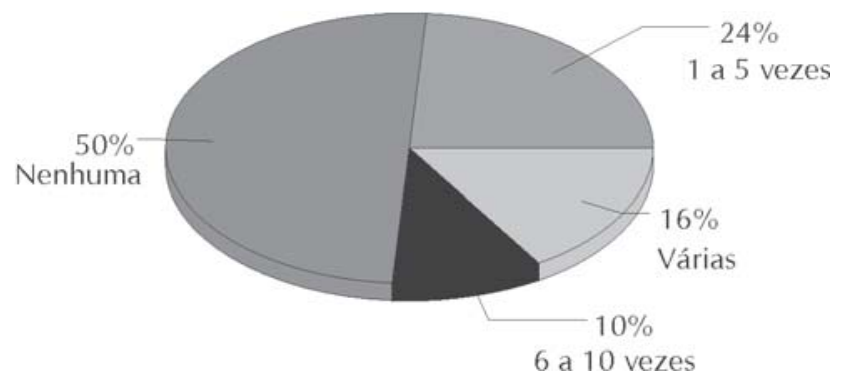

Gráfico 2: Histórico de internação psiquiátrica dos usuários durante o tratamento nos NAPS

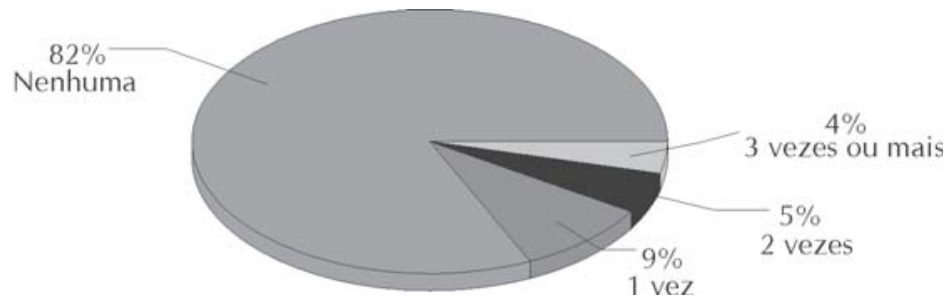


Observando o Gráfico 1, constatamos que $86 \%$ dos usuários dos novos serviços tinham histórico de internação psiquiátrica, $50 \%$ dos quais com um a cinco internações, $16 \%$ com várias internações e $10 \%$ com seis a dez internações. Apenas $24 \%$ dos usuários não tinham sido internados em instituições psiquiátricas tradicionais. Após ingressarem no NAPS, o número de internações reduz consideravelmente, uma vez que $82 \%$ dos usuários não precisaram de internação em nenhum momento do tratamento (Gráfico 2). As poucas internações de usuários atendidos pelos NAPS justificam-se, de acordo com a equipe de profissionais desses núcleos, por falta de recursos terapêuticos, como leitos em hospitais gerais ou Centros 24 horas, para acolhimento nas horas de crise. É evidente a eficiência dos serviços alternativos para evitar internações em sistemas manicomiais, como confirma este depoimento:

A eficácia do NAPS para evitar internação psiquiátrica pode ser vista a olho nu. O número dos nossos usuários que precisam de internação é muito reduzido... . Temos usuários que estão sendo atendidos pelo NAPS e nunca foram internados e usuários que pararam com as freqüentes internações, depois do tratamento nos NAPS. Isso prova a não necessidade dos hospitais psiquiátricos. (Roseane de Medeiros, arte-educadora)

Com o aumento da demanda e a euforia das conquistas, reforçaram-se as discussões e cobranças quanto à implantação de novos serviços que viriam complementar a rede de assistência. Até porque os NAPS, sem tal rede de apoio, começavam a esbarrar nos limites da sua atuação, criando-se um dilema diante das emergências e urgências psiquiátricas: inevitavelmente, a família acabava levando o usuário para o enclausuramento do hospital psiquiátrico, colocando em risco todos os ganhos de ressocialização obtidos durante a sua estada no NAPS. A reforma psiquiátrica precisava avançar, precisava consolidar os seus princípios e substituir por completo o modelo de assistência vigente. Os usuários precisavam contar com uma rede de apoio que não os deixasse desprotegidos, mas que também os fizesse sujeitos de seu processo de ressocialização. Eram necessários instrumentos que garantissem a conquista da cidadania a todos os portadores de doença mental. Era necessário assegurar a essas pessoas oportunidades de trabalho, de moradia e de vida dignas.

Nossa maior dificuldade é a falta de aparato social. Para onde vai o usuário depois do nosso trabalho? Num primeiro momento nós damos conta dessa demanda inicial. Um certo grau de socialização, a construção de um projeto pessoal, o resgate dos laços familiares - OK, damos conta. Mas depois, que recursos temos aí fora para dar continuidade ao nosso trabalho? (Roseane de Medeiros, arte-educadora) 
E, no entanto, não foi a consolidação dos princípios da reforma psiquiátrica que observamos a partir de então. Afinal, os hospitais psiquiátricos de todo o estado, principalmente os de Natal, continuavam abarrotados de leitos a um alto custo aos cofres públicos, como mostraremos no tópico seguinte. Por certo os novos serviços também eram procurados e cumpriam bem o seu papel, mas estavam (e ainda estão) longe de dar conta de toda a demanda. Além disso, serviços como os NAPS, exclusivos para portadores de sofrimento psiquíco, são insuficientes para desinstitucionalizar a loucura se faltam oportunidades de inclusão social desses indivíduos.

A partir do final de 1997 e início de 1998 e até os dias atuais, iniciou-se o quarto momento da reforma psiquiátrica no Rio Grande do Norte, o período de estagnação das propostas reformistas.

\section{Estagnação da reforma psiquiátrica no Rio Grande do Norte}

Entra-se então em uma fase de grande estagnação, no movimento iniciado em Natal. Projetos de criação de novos NAPS, bem como de demais serviços componentes de uma rede de atenção em saúde mental não conseguem sair do papel. Chegou-se a comprar todo o material e equipamentos necessários para a implantação de um NAPS na zona norte de Natal. Esse mesmo projeto passou seis meses com uma casa alugada, para colocá-lo em funcionamento, e ainda não foi implantado. Também houve um desmantelamento da rede proposta originalmente pela SMS, seja porque não ocorreu integralidade nas ações, ou devido a não implantação dos serviços.

Natal vem acompanhando a luta antimanicomial desde o seu início. No início de 90 houve um avanço muito grande, com a implantação dos serviços substitutivos. Dessa época para cá houve uma parada e a rede ficou descoberta. Continuam apenas os atendimentos dos psicólogos nas UBS e os dois NAPS implantados... . Então, em dez anos, dois NAPS e um CAPS. Poderia ter sido muito mais... . As pessoas estão muito desestimuladas. Está um marasmo, passamos esses últimos anos muito parados. (Aparecida França, ex-diretora do NAPS-Leste e secretária de Saúde de Natal)

A precariedade de um serviço público, mantido ou não segundo conveniências políticas, não é exclusividade da Secretaria Municipal de Saúde de Natal; é um problema sério em todo o país. Infelizmente o SUS, que poderia implantar uma verdadeira política nacional de saúde, vem sendo desmontado pelo boicote dos governos federal, estaduais e grande parte dos municipais. É inegável que a política nacional de saúde mental esbarra em dificuldades que 
influenciam o andamento das novas propostas, entretanto as especificidades da história local merecem análise mais cuidadosa.

A Coordenação de Saúde Mental atribui o fato às dificuldades de um período administrativo marcado por muitas greves e atrasos de salários. Do mesmo modo, as mudanças constantes de secretários municipais de saúde impediram a continuidade do trabalho e comprometeram a renovação de compromissos, como explicita este depoimento:

O que nos preocupa hoje é que a Secretaria, no nível de planejamento, está a desejar devido a problemas políticos e administrativos. Nós nos distanciamos das redes básicas, dos distritos, tentamos várias vezes e não conseguimos, porque eram greves sucessivas, atrasos salariais, seis secretários em cerca de um ano. E isso implica várias mudanças... implica definição político-administrativa, alugar uma casa para usuários, manter e renovar contratos, manter e renovar, de forma simbólica, a política de saúde mental a cada administrador que chegava lá... e significa também uma renovação de compromissos, para dar continuidade às equipes, aos profissionais... (Elisabete Freitas, ex-coordenadora de Saúde Mental)

A Coordenação de Saúde Mental entendia, então, que era hora de retroceder, pois o momento político era desfavorável a novos investimentos na área e que era preciso "cuidar" das conquistas que estavam consolidadas:

Nós avaliamos que precisávamos de mais pulso para poder caminhar. É sábio às vezes desacelerar, e nós desaceleramos também. (Elisabete Freitas, ex-coordenadora de Saúde Mental)

Cada conjuntura é uma conjuntura, tem momentos que a gente avança, tem momentos que a gente se sustenta... É uma grande luta para não desmanchar o que existe. Parece que não: “Ah, já foi feito, vou embora." Não. Já fez, agora cuide. E é esse cuidar que muitas vezes não acontece; inaugura-se a obra e vai-se embora. Cuidar dá mais trabalho que inaugurar... Você tem que se responsabilizar por dar uma resposta à sociedade. Você está oferecendo um serviço de qualidade e, para que ele continue assim, é preciso acompanhar. Então há conjunturas em que você cuida, não pode avançar muito, mas no processo histórico maior você está fazendo algo importante. Não temos que ter pressa, temos que ter a leitura do que é possível. (Maristela Pinheiro, coordenadora de Saúde Mental; grifos nossos)

De fato, na esfera política municipal mais ampla, tratava-se de um período muito conturbado, com inúmeros problemas administrativos que extrapolavam o campo da reforma psiquiátrica mas o influenciavam diretamente. No final da gestão do prefeito Aldo 
Tinoco (1.1.1993-31.12.1996), o posicionamento político das pessoas que estavam à frente da administração municipal e a forma como esta era conduzida trouxeram, na área da saúde pública, sérias conseqüências que afetaram inevitavelmente os serviços de saúde mental. A diretora do NAPS-Oeste então em exercício comenta as dificuldades enfrentadas:

Pelo menos até hoje, desde que estou na Secretaria, foi um dos períodos mais difíceis. A casa entrou num momento difícil no final da gestão de Aldo [Tinoco]. Faltavam comida, medicamentos, material de trabalho, porque os fornecedores não estavam recebendo e começaram a suspender o fornecimento. Faltava sabão para lavar louça, faltava remédio... (Verônica de Souza Pinheiro, ex-diretora do NAPS-Oeste)

Há que se entender que, para além da crise relacionada a questões macropolíticas do município, existiam outras questões inerentes ao momento de estagnação no qual mergulhava a reforma psiquiátrica. Este estudo permitiu identificar dois campos distintos de problemas que, apesar de se influenciarem mutuamente, merecem atenção e análise diferenciadas: (1) crises internas e específicas dos serviços e de sua equipe de profissionais; problemas institucionais e divergências teóricas; (2) influências externas advindas de interesses político-financeiros e de uma cultura manicomial instalada nas mentes tanto de profissionais quanto de leigos que estavam fora das discussões da reforma.

Sobre o primeiro campo de dificuldades, alguns depoimentos deixam claro que os serviços viviam crises internas muito fortes, o que acabou por abalar seu funcionamento. Uma das principais causas dos conflitos eram as relações de poder instauradas nos NAPS, geradoras de dificuldades, principalmente, para os profissionais de psicologia que se colocavam contrários a algumas posturas da equipe.

Havia um conflito de poder na equipe, e a nossa categoria esteve no centro dele: primeiro, por questionar a postura dos psiquiatras que passaram pela casa; segundo, por questionar a condução do restante da equipe. Isso gerava um incômodo muito grande, uma série de discussões... (Verônica de Souza Pinheiro, exdiretora do NAPS-Oeste)

A leitura que eu faço é que os profissionais não sabiam o papel de cada um, e isso os levou a entrar em choque. (Eline Montenegro, ex-psicóloga do NAPS-Oeste)

As equipes encontravam grandes dificuldades em trabalhar de forma multidisciplinar. As grandes divergências apareciam nos momentos de estudos de casos e de condutas de determinados usuários, quando havia uma expectativa, por parte da equipe, de que os 
encaminhamentos fossem decisões médicas. Os psicólogos, bastante numerosos na equipe cinco a seis em cada serviço), discordavam de vários encaminhamentos dados pelos psiquiatras, no que eram respaldados pelos demais profissionais.

Havia um desconforto muito grande por parte de algumas pessoas, evidente quando se questionava o posicionamento médico. Alguns médicos se mostravam visivelmente desconfortáveis quando questionávamos determinada conduta em relação ao usuário, e isso acabava gerando uma série de desdobramentos no dia-a-dia da casa. (Verônica de Souza Pinheiro, ex-diretora do NAPS-Oeste)

Parece que o 'monopólio' da psiquiatria sobre o campo da doença mental não havia sido perdido, mesmo com uma nova concepção de atenção à saúde mental. Que novo olhar sobre a loucura esses novos serviços estariam construindo? Ou, dito de outra maneira, que velhos preceitos e preconceitos esses novos serviços estariam reproduzindo?

Outros depoimentos mostram que havia certo receio da equipe em deixar os usuários 'andarem com as próprias pernas', o que nos leva a crer que o problema não estava apenas na falta de espaços de ressocialização, mas na crença ainda vigente sobre o pequeno potencial e autonomia dos portadores de doença mental. O trabalho em equipe ficava difícil, já que uma parte dela ainda estava bastante impregnada dos velhos significados sobre a loucura: "Algumas pessoas tinham uma postura de fazer as coisas pelos usuários. Era algo assistencialista, ou pressupunha que eles não eram capazes de fazer, de se desenvolver." (Eline Montenegro, ex-psicóloga do NAPS-Oeste)

O planejamento de assistência em saúde mental de Natal visava à "desinstitucionalização da doença mental" (Natal, 1992), proposta que ia além do processo de des-hospitalização. Ora, novas formas de atenção em saúde mental tendem a ser inócuas enquanto a cultura manicomial estiver presente no interior da própria SMS.

Passada a euforia inicial com a implantação dos serviços, a saúde mental e a reforma psiquiátrica como um todo deixaram de ser prioridades na agenda de saúde pública do município. Mesmo superada a crise político-administrativa do final da gestão de Aldo Tinoco, relatórios anuais dos NAPS apontam dificuldades internas em manter o serviço funcionando com qualidade. No final de 1997, primeiro ano da segunda gestão da prefeita Wilma de Faria, o relatório do NAPS-Leste mostra que as oficinas eram prejudicadas por falta de espaço apropriado e material. A estrutura física da casa tinha problemas que nunca haviam sido solucionados, como banheiros quebrados e problemas de esgoto, gerando reclamações constantes de usuários e técnicos. O relatório acrescenta: “Gostaría- 
3 Entendemos por abordagem 'clínica', neste contexto, a prática de atendimento individual, focalizada numa relação diádica. mos de ressaltar também que não foram raras as ocasiões em que a equipe teve que se cotizar para resolver problemas tão simples como, por exemplo, compra de lápis para o serviço." (Natal, 1997)

Outro problema que ocorria no NAPS-Leste era a divergência teórica a orientar os serviços, o que dividiu a equipe em dois blocos. Assim, enquanto no NAPS-Oeste brigava-se para derrubar a hegemonia do saber psiquiátrico em torno da loucura, no NAPSLeste observava-se uma clara divisão da equipe, baseada em linhas psicológicas diferentes. Um grupo defendia uma prática psicológica firmada nos princípios da psicanálise, em uma abordagem clínica $^{3}$; o outro grupo pretendia seguir à risca os ideais de ressocialização preconizados pela reforma psiquiátrica, em coerência a uma abordagem que priorizava trabalhos em grupos, como as diversas oficinas oferecidas nos NAPS. O depoimento a seguir parece atestar que a consolidação de uma prática da reforma psiquiátrica com base em uma teoria que a sustente é mais um desafio para os atores sociais envolvidos.

As discussões giravam, principalmente, em torno dos trabalhos em grupo e dos atendimentos individuais. "Por que priorizar grupos? A gente não tem que priorizar nada, nem atendimento individual, nem grupos. A gente tem que oferecer essas atividades e o paciente escolhe." Mas havia, por parte da equipe e da Coordenação de Saúde Mental, uma total resistência ao atendimento individual. Na minha interpretação era uma resistência, um equívoco mesmo. $\mathrm{O}$ argumento era que o paciente só se ressocializa se participa de atividades em grupo. De dez atividades, nove eram trabalhos em grupo, entre oficinas e grupos terapêuticos, e apenas uma era atendimento individual - isso não era suficiente. (Wagner Lima, ex-psicólogo do Naps)

As dificuldades de diálogo nessa fase da reforma psiquiátrica desgastaram as relações entre os profissionais e desacreditaram muitos dos que lutavam para a efetivação dos princípios desse movimento e eram importantes atores no cenário local. Muito do vigor da reforma foi perdido com a saída de técnicos que nela haviam se engajado.

O estudo que realizamos revelou também claramente que a discussão da reforma psiquiátrica em Natal, assim como em todo o estado, passa longe da participação efetiva dos usuários e seus familiares. A pálida participação destes no processo de reforma psiquiátrica, sua quase imperceptível atuação do movimento antimanicomial podem explicar, em grande parte, a estagnação da reforma psiquiátrica no Rio Grande do Norte. Os movimentos sociais só se consolidam e adquirem importância política se são movimentos de base, se conseguem construir sua sustentação nas bases. Não foi o que ocorreu no processo de reforma psiquiátrica no Rio Grande do 
Norte. O Movimento de Luta Antimanicomial (MLAM) congregou apenas técnicos, e o afastamento destes, nos serviços, ocasionou uma retração da causa. O papel dos usuários e familiares no movimento da reforma psiquiátrica é historicamente importante, por isso em momento algum o MLAM poderia ser apenas um movimento de técnicos. Seu interesse central precisa ser partilhado com usuários e familiares. Afinal, que conquista de cidadania se espera se estes não forem os verdadeiros protagonistas, na história da revolução da assistência em saúde mental? Além disso, mesmo considerando o âmbito essencialmente técnico, o MLAM mostrou-se, durante todo esse processo, desarticulado, frágil e sem expressão política. Somente a organização política dos demais setores da sociedade pode modificar substancialmente as políticas de interesse da população. Não será diferente para a reforma psiquiátrica, que necessita condições reais para a articulação de uma rede de serviços que vise à superação do modelo manicomial.

\section{Considerações finais}

Não serei o poeta de um mundo caduco. Também não cantarei o mundo futuro. Estou preso à vida e olho meus companheiros. Estão taciturnos mas nutrem grandes esperanças.

Entre eles, considero a enorme realidade. O presente é tão grande, não nos afastemos. Não nos afastemos muito, vamos de mãos dadas.

("Mãos dadas", Carlos Drummond de Andrade)

A realidade social brasileira e o modelo econômico vigente, que acentua as desigualdades sociais e aumenta a exclusão, não podem ser desvinculados das dificuldades que enfrenta atualmente a reforma psiquiátrica. Nas palavras de Matos (1999, p.38), "um mundo no qual só conta a lei do valor não é o mundo humano mas do capital". Logo, a cidadania plena é ainda sonho distante, não só para os portadores de doença mental, mas para inúmeros brasileiros.

O quadro mundial da última década, com o avanço do neoliberalismo e da globalização, vive um grande paradoxo ao trazer de volta políticas sociais austeras, conservadoras e limitadas. Não ficam de fora dessa configuração a área de saúde nem a saúde mental. Os anos 90 não foram favoráveis, por exemplo, para a participação política, para a implantação de sistemas democráticos universalistas e para financiamentos direcionados ao setor público. Pelo contrário; as reformas ocorridas no Brasil levaram a privatizações e à redução nos gastos públicos.

A experiência de reforma psiquiátrica em Natal, bem como em todo o estado do Rio Grande do Norte, faz parte desse contexto macropolítico e subordina-se à vontade política dos gestores de 
saúde e aos rumos da economia brasileira. No entanto foi preciso olhar essa experiência de reforma também nas suas especificidades, e a análise demonstrou claramente que o movimento de reforma psiquiátrica, no estado, esqueceu-se de fazer novas construções teóricas e operacionais, no plano de assistência em saúde mental. A promoção à saúde, a integração de práticas e a participação social devem estar presentes na nova agenda de saúde mental. É preciso, também, construir novos conhecimentos, novos saberes e novas práticas, para superar a crise em que se encontra o movimento local de reforma psiquiátrica.

Neste ponto, faz-se mister afirmar que momentos de estagnação e de crise também podem ser momentos de criação, em que encontramos soluções mais elaboradas para o problema que se coloca diante de nós. Acreditamos estar diante de um momento desses, no qual paramos, olhamos para trás, revemos algumas falhas e vislumbramos saídas criativas para a superação da realidade.

Culturas manicomiais enraizadas em mentes e instituições durante anos não são solúveis facilmente. No entanto é preciso não se deixar vencer por comodismo, apatia e ceticismo. Afinal, a reforma psiquiátrica é um processo de constante reflexão e construção de saberes sobre a loucura e seu lugar social.

Guirado (1999) pergunta-se se apenas os militantes poderiam falar sobre luta manicomial e em que a universidade pode contribuir com essa luta. "A Universidade deveria engrossar coro de vozes" (p.124), responde ela. De fato, a universidade não pode eximir-se dessa discussão, tendo em vista que é a agente formadora dos profissionais que fazem (fizeram e farão) a reforma psiquiátrica. É a universidade quem precisa promover uma ruptura radical com alguns saberes consolidados da psiquiatria e da psicologia: “Neste contexto, mais do que nunca é preciso preservar a universidade como lugar de resistência, de necessária contestação. Resistência que assuma, sobretudo, a forma de insistência em pensar, de reflexão teimosa..." (Patto, 1999, p.118). Sem dúvida, a psicologia pode contribuir muito com esse processo. Porém é preciso repensar práticas. A profissão caracterizou-se durante anos por uma passividade excessiva, uma espera incômoda de que o adoecer viesse bater à sua porta.

Assim, o afastamento dos portadores de doença mental e dos considerados 'normais' deve ser evitado. Que não se distanciem tanto, que caminhem de 'mãos dadas', em busca da concretização do princípio da dignidade humana, direito de todos, como nas sábias palavras de Carlos Drummond de Andrade. 


\section{REFERÊNCIAS BIBLIOGRÁFICAS}

Amarante, Paulo 1997

Amarante et al. 2001

Guirado, Marlene 1999

Lobosque, Ana Marta 2001

Matos, Olgária C.F. 1999

Natal 1997

Natal 1992

Patto, Maria Helena S. 1999

Silva, Rosalina C. da 1998
Loucura, cultura e subjetividade: conceitos e estratégias, percursos e atores da reforma psiquiátrica brasileira. In: Fleury, Sonia (Org.). Saúde e democracia. São Paulo: Lemos. p.163-185.

Metamorfose ou invenção: notas sobre a história dos novos serviços em saúde mental no Brasil. In: Jacó-Vilela, Ana Maria; Cerezzo, Antonio Carlos; Rodrigues, Heliana de Barros Conde (Org.). Clio-Psyché hoje: fazeres e dizeres psi na história do Brasil. Rio de Janeiro: Relume Dumará. p.51-63.

Universidade e luta antimanicomial. In: Fernandes, Maria Inês; Scarcelli, Ianni R.; Costa, Eliane Silvia (Org.). Fim de século: ainda manicômios? São Paulo: Ipusp. p.123-130.

Experiências da loucura. Rio de Janeiro: Garamond.

Cidadania: espaço público e tolerância mestiça. In: Fernandes, Maria Inês; Scarcelli, Ianni R.; Costa, Eliane Silvia (Org.). Fim de século: ainda manicômios? São Paulo: Ipusp. p.47-53.

Secretaria Municipal de Saúde. Relatório das atividades do Núcleo de Atenção Psicossocial do ano de 1997. Natal: SMS.

Secretaria Municipal de Saúde. Proposta de reorganização da atenção em saúde mental no município de Natal. Natal: SMS.

Formação profissional, compromisso político e luta antimanicomial. In: Fernandes, Maria Inês; Scarcelli, Ianni R.; Costa, Eliane Silvia (Org.) Fim de século: ainda manicômios? São Paulo: Ipusp. p.109-122.

A formação em psicologia para o trabalho em saúde pública.

In: Campos, Florianita C.B. (Org.). Psicologia e saúde: repensando práticas. São Paulo: Hucitec. p.25-40.

Recebido para publicação em dezembro de 2004. Aprovado para publicação em dezembro de 2005. 